\title{
Smoldering Spot Ignition of Natural Fuels by a Hot Metal Particle
}

\author{
James L. Urban ${ }^{\mathrm{a}, *}$, Casey D. Zak ${ }^{\mathrm{a}}$, Jiayun Song ${ }^{\mathrm{b}}$, Carlos Fernandez-Pello ${ }^{\mathrm{a}}$ \\ ${ }^{a}$ Department of Mechanical Engineering, University of California - Berkeley, Berkeley, CA \\ 94720, USA \\ ${ }^{b}$ State Key Laboratory of Fire Science, University of Science and Technology of China, Hefei \\ 230026, China
}

\begin{abstract}
The spotting ignition of combustible material by hot metal particles is an important pathway by which wildland and urban spot fires are started. Upon impact with a fuel, such as dry grass, duff, or saw dust, these particles can initiate spot fires by direct flaming or smoldering can transition to flaming. In spite of the relative frequency that fires are initiated by hot metal particles, there is little work published that addresses the ignition capabilities of hot metal particles landing on natural fuels, especially regarding smoldering ignition. This work is an experimental and analytical study of how the flaming and smoldering propensities of powdered natural fuel beds in contact with hot metal particles are affected by differences in the particle characteristics, particularly the effect of particle melting, which adds energy to the particle. In the experiments, stainless steel and aluminum particles particles ranging in size from 1.6 to $8 \mathrm{~mm}$ in diameter are heated to various temperatures between 500 and $1100^{\circ} \mathrm{C}$ and dropped onto a fuel bed composed of a powder grass blend. It is observed that the ignition boundary both for flaming and smoldering follows a hyperbolic relationship between particle size and temperature, with smaller particles requiring higher temperatures to ignite the fuel. For both metal particles smoldering ignition occurs at significantly lower temperatures than flaming ignition. A simplified numerical model is developed to help understand smoldering ignition by a metal particle and to examine how the
\end{abstract}

${ }^{*}$ Corresponding author. Fax +15106421850

Email address: Jlurban@berkeley .edu (James L. Urban ) 
melting influences the ignition process. Good qualitative agreement is obtained between the model predictions and the experiments suggesting that the model provides a first step toward the theoretical modeling of this complex problem.

Keywords:

Spot Fire Ignition, Wildland Fires, Biomass Combustion, Smoldering Ignition, Wildland Urban Interface Fires

\section{Nomenclature}

\section{Symbols}

$\Delta H \quad$ Change in enthalpy $[k J / k g]$

$\dot{\omega}_{j} \quad$ Reaction rate of the $j^{\text {th }}$ reaction $\left[\frac{\mathrm{kg}}{s * m^{3}}\right]$

$\nu \quad$ stoiciometric coefficient [-]

$c_{p} \quad$ Specific Heat Capacity $[J /(k g-K)]$

$k \quad$ Thermal conductivity $[W /(m-K)]$

$R_{p} \quad$ Metal Particle Radius [m]

$T \quad$ Temperature $[K]$

$Y_{i} \quad$ Mass fraction of $i^{\text {th }}$ solid specie [-]

$Y_{\mathrm{O}_{2}} \quad$ Mass fraction of Oxygen [-]

\section{Superscripts \& Subscripts}

$\hat{X} \quad$ local volume average of $X$

$X_{g} \quad$ gas domain value of $X$

$X_{i} \quad i^{\text {th }}$ solid specie of $X$ for $\mathrm{i}$ in (virgin, char, or ash)

$X_{j} \quad j^{\text {th }}$ reaction

$X_{p} \quad$ particle domain value of $X$

$X_{s} \quad$ solid fuel domain value of $X$ 


\section{Introduction}

The ignition of natural fuels by hot metal particles is an important fire ignition pathway by which wildland and urban spot fires are started. The literature contains lists of fires initiated in this manner [1-12], but even more remain unreferenced due to their involvement in litigation. According to published data [13, 14], powerlines, equipment, and railroads cause approximately 28,000 natural fuel fires annually in the United States, and the established literature discusses many other potential hot particle sources [9--12]. With current drought conditions in much of the western area of the United States, the danger of wildfires has continued to increase. In September of 2015, the Butte fire burned over 28,000 hectares in California, and there have been reports that powerline interactions were likely the cause [15]. Other examples of fires started by particles produced by powerlines include the Witch Creek and Guejito fires burned almost 81,000 hectares and destroyed over 1,100 homes during the 2007 California firestorm. According to reports by The California Department of Forestry and Fire Protection (CalFire) and NIST, both fires were allegedly started by hot metal particles generated by powerlines [2, 3]. Another recent large wildland/urban fire is the Bastrop County Complex wildfire in Texas; it burned 12,787 hectares in 2011. The fire allegedly started when powerlines interacted with each other and nearby trees during high winds. The resulting sparks ignited dried grass and vegetation [4]. Hot metal particles and sparks produced by hot work have also been involved in several notable incidents, such as the Taylor Bridge fire in Washington state which was reportedly caused by sparks from rebar cutting or welding [16]. Wildland fires in many other countries, particularly New Zealand and Australia, have been caused by hot particle spot ignition [7, 8]. 
There are a limited but growing number of studies published on the spot ignition of natural fuels by hot metal particles by the present authors and others. Most have studied the problem through experiments [17--25], but there has also been some of modeling of the phenomena, with several simplified models ranging in success and complexity. "Hot spot" models originally used to model sympathetic detonation of explosives [26] have been adapted to the ignition of natural fuels by hot metal particles [19, 27] with limited success. More elaborate 1-D models have also been developed for flaming ignition [28]. A related problem is the spot fire ignition of polymer foams found in industrial and urban environments has also been studied [29-31].

The ignition of a solid fuel by a hot metal particle is very complex. Once the particle lands on the fuel, energy is transferred from the particle to the fuel and ambient surroundings and the particle temperature decreases. If the fuel is raised to a high enough temperature, it decomposes into solid intermediates, char, and gaseous volatiles. The volatiles mix with the air and may generate a flammable gas mixture near the particle. If the particle is hot enough it can ignite the gaseous mixture through either a piloted or auto-ignition process. Even if gas-phase ignition does not occur, oxidation of the remaining char can generate enough heat to establish a smoldering front. The smoldering front may transition to a flame if there is a flammable gas mixture near the smoldering front. This complex multiphysics ignition process depends on many factors, including the size and state of the particle (temperature, molten/solid, oxidizing), the characteristics of the fuel on which it lands (composition, morphology, density, porosity, moisture content), the characteristics of the particle landing (fully or partially embedded in the fuel, bouncing, splashing, rolling) and environmental conditions (temperature, humid- 
ity, wind velocity).

Any study of such a complex process must be parameterized. In this study, the ability of hot metal particles to initiate a smolder or flame in a porous fuel is investigated through experiments and smoldering ignition is examined further through modeling. Stainless steel and aluminum particles were chosen for this study because aluminum melts in the range of temperatures studied while stainless steel does not and because these metals are representative of particles produced by power transmission lines and sparks from machine friction.

\section{Experiments}

A schematic of the experimental apparatus is shown in Fig. 1. The apparatus consists of a bench scale wind tunnel where the fuel bed is mounted flush with the floor of the tunnel test section. The wind tunnel is $55 \mathrm{~cm}$ long with a $13 \mathrm{~cm}$ by $8 \mathrm{~cm}$ cross section. The fuel sample holder is $15 \mathrm{~cm}$ long, $10 \mathrm{~cm}$ wide and $5 \mathrm{~cm}$ deep and its leading edge is $15 \mathrm{~cm}$ from the inlet of the tunnel. A tube furnace is used to heat the metal particles. A linear guide holds a long handled ceramic crucible approximately $14 \mathrm{~cm}$ above the fuel bed. The guide allows for the crucible to be easily inserted and removed from the furnace. A type $\mathrm{K}$ thermocouple is embedded in the crucible to provide a measurement of the particle temperature. The particles are heated in the furnace until their temperature reaches equilibrium conditions as indicated by the thermocouple in the crucible. It should be noted that the particle temperature reported here is that of the particle in the oven, not at landing. The particle temperature at landing is obviously lower and dependent on the particle size, temperature and emissivity. A conservative estimate of the reduction in temperature due to convective and radiative heat losses was made 


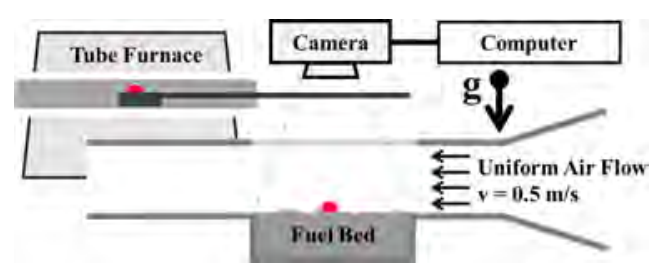

Figure 1: Schematic of experimental apparatus

assuming the particle was thermally uniform as it fell from the crucible to the fuel. The estimated reduction temperature was found to be no more than $50^{\circ} \mathrm{C}$ and $90^{\circ} \mathrm{C}$ for aluminum and steel particles respectively. The fuel can be imaged from a camera above through the open top from which the particles are dropped (Fig. 1). The camera records images of the tests at regular intervals and captures visible and infrared (IR) light. This allows for visualization of charring of the solid fuel, and heat losses by IR radiation. These pictures provide qualitative data about the temperature of the particle and the presence of solid phase exothermic reactions.

Lab air flows through the wind tunnel with a centerline velocity of $.5 \mathrm{~m} / \mathrm{s}$ at the leading edge of the fuel for all tests. As alluded to above, the air flow velocity is one of many important parameter affecting the ignition process; it affects the rate of cooling of the particle and the generation of the flammable gaseous mixture and establishment of a smoldering front near the particle. The air velocity in this study was chosen because it produces a uniform flow without disturbing the surface of the fuel. Because of the low flow velocities, caution should be exercised when applying these results to situations with higher cross-flow velocities. Flow uniformity is affected by the open tunnel top used to introduce the particles. To reduce this irregularity and ensure a uniform cross-flow velocity, particles are only dropped on the leading half of the fuel bed. The relative humidity and temperature 
of the flow were measured daily and found to be on average $31 \pm 6 \%$ and $24 \pm 3^{\circ} \mathrm{C}$ respectively.

For this study, we used particles composed of stainless steel alloy 302 and 304 [32] and aluminum alloy 1100 [32, 33]. The thermal properties are given in Table 1. The particles in this study are spherical and range in size from 1.6 to $8.0 \mathrm{~mm}$ in diameter. The temperatures tested range from 500 to $1100^{\circ} \mathrm{C}$. The maximum temperature is limited by the maximum operating temperature of the furnace. The fuel is a powder formed by grinding a grass blend. The fuel beds were initially bone-dried and then allowed to come to a moisture equilibrium with the laboratory. The moisture content (mass of water to fuel dry mass) of the fuel was measured each day tests were conducted and the average moisture for a test was $8.0 \pm 2.0 \%$. In order to minimize the effects of random variations in the fuel beds and the penetration of the particle into the fuel, the location where the particle was dropped was varied and no more than two tests of the same condition were done on a single fuel bed.

Five tests were done at each test condition to determine a probability of ignition. Each test could have one of three outcomes: Flaming Ignition (FI), Smoldering Ignition (SI) or No Ignition (NI). The establishment of self propagating flame spread or large scale smolder spread was not studied here, nor was the possible outcome of a smolder transitioning to a flame. Each of these phenomena are sufficiently complex as to deserve their own study. FI was defined by a flame that persisted for at least $1 \mathrm{~s}$. The definition of SI is more difficult because selfsustained smoldering occurs in an opaque medium and is difficult to distinguish from thermal decomposition driven by heat transfer from the particle.

One approach, used in [34] to ensure that a smolder is propagating indepen- 
dently from its ignition source is to wait for an extended period of time $\left(>10^{3} \mathrm{~s}\right)$ until the smolder either consumes the entire fuel sample or extinguishes. Due to the large number of tests conducted in this study, we recorded SI when the visible char layer surrounding the particle had a thickness greater that the particle diameter and observed movement of the smoldering front and pyrolyzate production. This criteria was supported by readings from the IR camera, which showed increasing temperatures after a period of cooling. As a final check, a handful of tests were performed where the smoldering front was allowed to propagate freely through the entire sample over the course of $1 \mathrm{hr}$. A further discussion of the smoldering ignition behavior and associated ignition criteria can be found in Sec. 4

\section{Model Description}

Smoldering ignition of the fuel is simulated with a simplified 1-D spherical model accounting for porous heat and oxygen mass transfer with a 3-step reaction model. The metal particle was assumed to be thermally lumped and completely surrounded by a layer of virgin material. The outer surface of this virgin material was exposed to air at STP. The particle is fully submerged in the fuel and only cools by transferring heat to the surrounding material; volatiles that are produced are assumed to instantly leave the domain, oxygen is able to diffuse in from the outer boundary, and the gas phase the density, $\rho_{g}$ was assumed to be constant. The governing equations of this system are the conservation of energy in the particle, in the solid domain, species conservation in the solid and gas phases.in Eqns. 2]4. 


$$
\begin{gathered}
\left.\frac{\partial T_{p}}{\partial t}\right|_{r=R_{p}}=\left.\frac{12 \hat{k_{s}}}{\rho_{p} c_{p_{e f f}\left(T_{p}\right)} R_{p}} \frac{\partial T_{s}}{\partial r}\right|_{r=R_{p}} \\
\frac{\partial T_{s}}{\partial t}=\frac{\hat{k_{s}}}{r^{2}} \frac{\partial}{\partial r}\left(r^{2} \frac{\partial T_{s}}{\partial r}\right)+\sum_{j} \frac{\Delta H_{j} \dot{\omega}_{j}}{\left(\hat{\left.c_{p}\right)_{s}}\right.} \\
\frac{\partial Y_{s, i}}{\partial t}=\sum_{j} \frac{\nu_{i, j} \dot{\omega}_{j}}{\hat{\rho}_{s}} \\
\frac{\partial Y_{O_{2}}}{\partial t}=\frac{\hat{\psi} D_{O_{2}} \rho_{g}}{r^{2}} \frac{\partial}{\partial r}\left(r^{2} \frac{\partial Y_{O_{2}}}{\partial r}\right)+\sum_{j} \frac{\nu_{j, O_{2}} \dot{\omega}_{j}}{\rho_{g} \hat{\psi}} \\
\dot{\omega}_{j}=Z_{j}\left(1-\alpha_{j}\right)^{n_{j}}\left(\frac{Y_{O_{2}}}{.23}\right)^{n_{O_{2}, j}} \exp \left(\frac{-E_{j}}{R T_{s}}\right) \\
r=R_{p} \mid T_{s}=T_{p, o}, \quad Y_{O_{2}}^{\prime}=0 \\
r \rightarrow \infty \mid T_{s}=T_{\infty}, \quad Y_{O_{2}}=.23(\text { Air }) \\
t=0 \quad \mid T_{s}=T_{\infty}, Y_{O_{2}}=.23, Y_{v i r g}=1
\end{gathered}
$$

where $c_{p, e f f}\left(T_{p}\right)$ is an effective specific heat capacity of the particle and $k$ is the effective thermal conductivity which accounts for pore radiation as was done in [28]. For steel it was a constant value, while for the aluminum, which melts over the temperature range $643-657^{\circ} \mathrm{C}$, the value changes to account for differences in the heat capacity and energy added from melting, $390 \mathrm{~kJ} / \mathrm{kg} . D_{\mathrm{O}_{2}}$ is the mass diffusivity of $\mathrm{O}_{2}$ in air and taken to be a constant. $\alpha_{j}$ is the consumption of the $j$-th solid specie. The initial and boundary conditions are shown in Eqns. 6- 8,

The solid phase was considered to be comprised of three components: Virgin, Char, and Ash with properties show in Table 1 . The virgin material corresponds 
Table 1: Properties of the fuel species and the particle metals: stainless Steel 302/304 and aluminum 1100. Molten properties shown in parentheses.

\begin{tabular}{llllll}
\hline Material & Virgin & Char & Ash & Steel & Al. 1100 \\
\hline$\rho$ & 260 & 90 & 15 & 7860 & $\begin{array}{l}2710 \\
(2375)\end{array}$ \\
{$\left[k g / m^{3}\right]$} & & & & & 900 \\
$c_{p}$ & 1400 & 1600 & 1800 & 500 & $(1141)$ \\
{$[J / m K]$} & & & & & 220 \\
$k$ & 0.1 & 0.07 & 0.06 & 21.5 & $(90.7)$ \\
{$[W / m K]$} & & & & & n/a \\
$\psi[-]$ & 0.35 & 0.78 & 0.94 & /a & n
\end{tabular}

Table 2: Parameters for Eqn. 5. 1) Thermal Pyrolysis and 2) Oxidative pyrolysis and 3) Ashing reactions, values from [35]

\begin{tabular}{llllll}
\hline \multirow{2}{*}{$j$} & $\Delta H$ & $Z$ & $E$ & \multirow{2}{*}{$n$} & $n_{O_{2}}$ \\
& {$[k J / k g]$} & {$[1 / s]$} & {$[k J / m o l]$} & & \\
\hline 1 & 0.2 & $10^{6.34}$ & 105 & 0.87 & 0 \\
2 & -4.3 & $10^{8.72}$ & 128 & 0.56 & 0.72 \\
3 & -11.9 & $10^{6.55}$ & 124 & 0.63 & 0.68 \\
\hline
\end{tabular}

to the unreacted fuel bed which can react through both thermal and oxidative pyrolysis reactions producing Char, which in turn can undergo oxidative reactions producing Ash. This type of 3-step mechanism been applied in other studies of smoldering biomass [35, 36], and the thermo-chemical parameters used in this study are given in Table 2 .

The governing equations were solved with an implicit finite volume scheme adaptive time stepping. Simulations were performed for particle sizes and temperatures in the same range of those done in the experiments. The minimum initial particle temperature was determined, within $1^{\circ} \mathrm{C}$ of precision. SI was determined by checking if the smolder would propagate at least $10 \mathrm{~mm}$ from the particle and show steady or accelerating smolder propagation at this point. The subsequent smolder propagation was not modeled. Simulations were also conducted to ob- 
serve the events leading up to the initiation of the smoldering front. The computational domain was $37.5 \mathrm{~mm}$ from the surface of the particle and divided into $10^{3}$ cells for all simulations.

\section{Results \& Discussion}

The primary goal of this work is to identify the required particle temperature to ignite natural fuels with a smolder, but for completeness flaming ignition data is also shown. It is interesting to note that during FI events, the flame on occasion receded to a smolder after roughly 10s. During each test, the progress of the char front on the surface of the fuel was captured with the overhead camera and two distinct phases of the SI process were observed (see Fig. 2. Immediately after landing the the particle rapidly heats the surrounding fuel and a char shell (typically at least $1 \mathrm{~mm}$ thick) forms around the particle. This initial smolder will cease to propagate and different sized particles display different behavior. Experiments with small particles will rapidly, in roughly 10s, develop a 'hot node' - a small localized smolder along the perimeter of the char shell which will start to propagate. Experiments with large particles will develop a hot node after a considerably longer time, often as long as 300s, after they impact during which time they cool significantly. The fact that the initial radial smolder stops and then a secondary smolder, that is self-sustaining, begins later at one location around the char shell indicates that there is a process hindering the smolder. In the first three images of the top and bottom of Fig. 2, we see that the particle cools significantly during the course of a test. If a particle cools enough, it could be colder than the temperature of the incipient smolder and heat transfer back to the particle from the smolder might hinder or even prevent the final step of the smoldering ignition. We can ex- 
amine the effect of heat losses back to the particle through the modeling. Fig. 3 , shows the temperature profile of the fuel for a SI case (left) and a NI case (right). The temperature at $(\mathrm{x}=0)$ is the temperature of the particle and we can see for the SI case (i) that the particle temperatures initially falls as that energy heats the fuel near the particle. When SI occurs the we see a momentary local maximum in the temperature profile (ii) and then we see the particle temperature rise again (iii) and the reaction front begins to propagate. However, the inherent 1-D aspect of the model does not allow it to explain why the secondary self-sustaining smolder starts at only one point from the initial smolder. This is likely caused by small local variations in the fuel bed which cause only one region along the char shell to be viable for the secondary self-sustaining smolder and also by the effects of subsurface smoldering which cannot be visualized by the current model and experimental apparatus. In both the model and the experiments, NI events exhibited the rapid initial radial smolder as with the the SI events as shown in the third frame from the left of both the top and bottom of Fig. 2 for experiments and the initial spread shown by the model in Fig. 3 for the model (iv, v). The smoldering ignition phenomena of the aluminum particles was very similar to those with steel, with exception of the tests where a relatively large aluminum particle was molten. For these experiments there a thicker char shell developed rapid when the particle impacted the fuel, indicating that the energy from melting helps initiate the smolder considerably.

The experimental ignition results are presented in Fig. 4. Black circles or squares indicate that no SI or FI events, respectively, were observed and conversely, white circles and squares indicate that all the tests resulted in a SI or FI, 


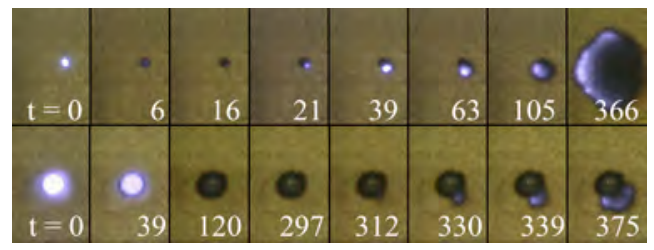

Figure 2: Images of surface smolder spread of a $1.6 \mathrm{~mm}$ steel particle at $1000^{\circ} \mathrm{C}$ (top) and a $8 \mathrm{~mm}$ particle initially at $600^{\circ} \mathrm{C}$ (bottom). The white light is IR light captured by the camera and not visible to the bare eye. Time from impact is shown in seconds for each frame. Note: airflow is coming in from the left. Frames 1-3: Initial cooling for both particles. For the small particle the hot node develops $21 \mathrm{~s}$ after the particle cools in frame 4 and the hot node develops at 330s after impact for the large particle in frame 6 . Subsequent smolder spread is shown in remaining frames.
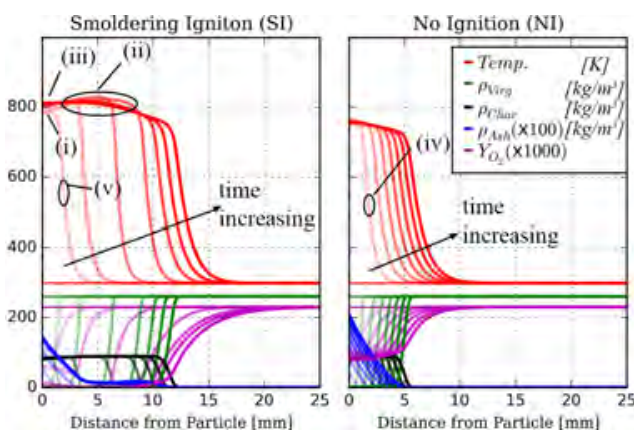

Figure 3: Time evolution of 1-D simulations. Both simulations are of $7 \mathrm{~mm}$ particles. The initial temperature of the particle on the left was $536^{\circ} \mathrm{C}$ which resulted in SI and the particle on the right was initially at $531^{\circ} \mathrm{C}$ and resulted in NI. The solution profiles are spaced $10 \mathrm{~s}$ apart and total time shown in figure is 70s. (i) initial particle cooling due to heat loss to the fuel, (ii) momentary increase in smolder temperature, (iii) particle is heated by the smolder. (iv) \& (v) initial smolder/thermal degradation due to heat from the particle 
(a) Stainless Steel
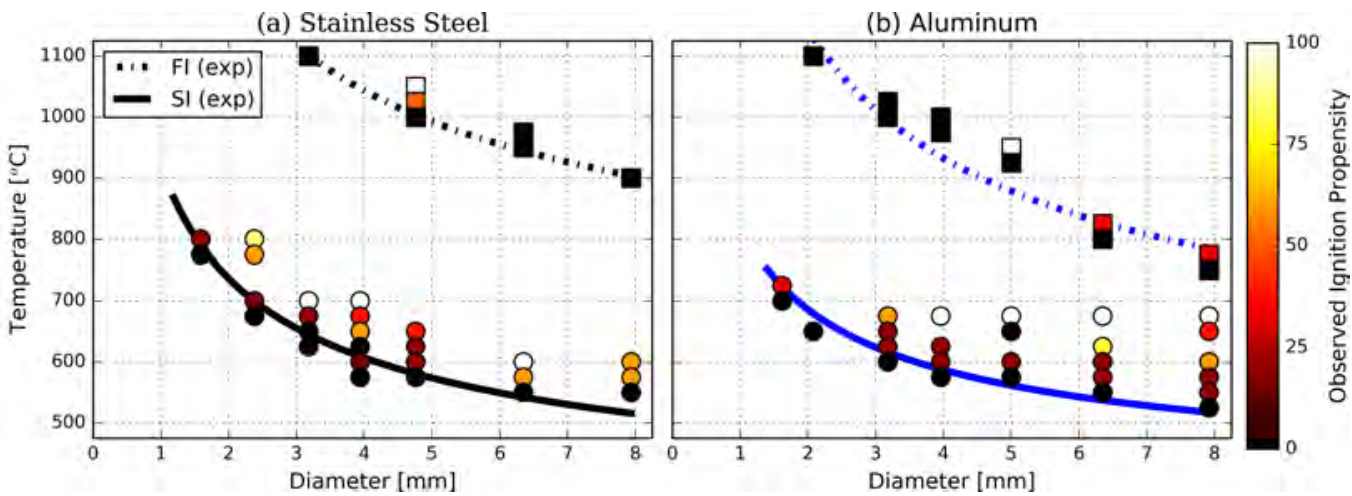

Figure 4: Observed Ignition Propensity for (a) Stainless Steel \& (b) Aluminum. The squares and circles are colored according to the fraction of the tests that resulted in FI or SI, respectively. Each marker corresponds to at least five tests at that test condition. Ignition boundaries for FI are shown with the dashed lines and for SI with solid lines.

respectively. The data is used to find the SI or FI boundaries for the fuel in contact with each type of particle. The ignition boundaries are found by fitting a curve through the data points. Determining precise FI and SI boundaries is difficult as there is a range of test conditions where both SI \& NI or FI \& SI events were observed. This range is indicative of our ability to control the different parameters of the problem such as the exact fuel porosity at the landing location, variations in the moisture content and ambient conditions. It is possible to use statistical methods to try and determine an average or 50\% ignition boundary. In order to do this assumptions must be made regarding the distribution of the variation with respect to each of these parameters/confounding variables and then how precisely they impact the ignition process. In this study we have chosen simply to report ignition boundaries determined by finding a set of maximum temperatures for various particles sizes which did not ignite for at least five tests. We feel that determining the ignition boundaries this way is practical as it reports minimum conditions found to initiate ignition for the study and the criteria for choosing it is simple and well defined. 

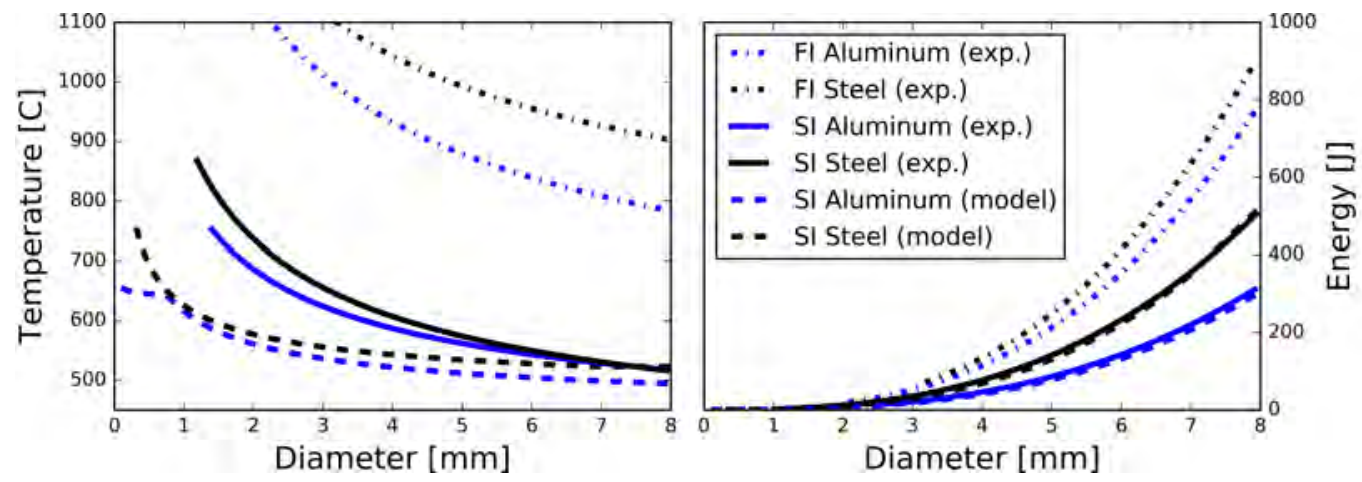

Figure 5: Temperature-diameter (a) and Energy-diameter (b) ignition boundaries for Aluminum (blue) and Steel (black) for FI and SI from experiments and SI from the model.

The FI and SI boundaries for each metal type follow the same trend observed in previous work on SI [17, 19] and FI [17, 19, 22] of different fuels. There is a monotonic decrease in the required particle temperature for both SI and FI as the particle size is increased and FI requires higher particle temperatures than SI. We can see that smaller particles had a much larger range of temperatures at which ignition could occur while the range was much smaller for larger particles. At temperatures above $643^{\circ} \mathrm{C}$ the aluminum alloy used will start to melt, because it is an alloy it melts over a temperature range $\left(643-657^{\circ} \mathrm{C}\right)$. We assumed the energy added by melting over this range was linear with respect to temperature. The energy from melting is a likely explanation of why for particle temperatures greater than or equal to $650^{\circ} \mathrm{C}$ aluminum particles were able to ignite at lower temperatures than their steel counterparts.

The ignition results from the show qualitative agreement the experiments. Overall the model predicts ignition at lower temperatures than the experiments. The agreement is within $50^{\circ} \mathrm{C}$ for particles larger than $4 \mathrm{~mm}$. For smaller particles, the model predicts a lower temperatures required for ignition. The likely explanation for this is the cooling of the particle as they fall from the crucible to 
the fuel. In the case of small particles, higher temperatures are required and the thermal mass of the particle is relatively low so the heat loss rate to the ambient surroundings are more significant than the heat losses for larger, cooler particles. The model presented here is limited as it does not resolve these heat losses. Another limitation of the model that is presented here are the details of the thermal contact between the particle and the surrounding fuel. The complexities of considering radiative heat transfer from the hot particle and the fuel as studied in [37] were not examined here.

One clear difference in the SI boundaries of the model and experimental data is the clear effect of melting. The model's SI boundary is nearly a horizontal line for particles smaller than $1 \mathrm{~mm}$ in size. This behavior was not observed in the experimental SI boundaries. However the effect of melting can be seen in the upper boundary, showing the minimum temperature where ignition happened during each test. Denoted by the white circles in Fig. $4 \mathrm{~b}$, we can see that for aluminum particles larger than $3 \mathrm{~mm}$ in diameter, particles heated to $675^{\circ} \mathrm{C}$, the lowest temperature above aluminum's melting range, always ignited while the tests performed $25^{\circ} \mathrm{C}$ lower had a lower observed ignition probability indicating that the energy added by melting also increases the likelihood of ignition. This effect has also been noticed by the authors for the FI of pure cellulose powder fuels and it was noted that the latent heat of melting adds energy equivalent to the energy gained from heating the aluminum particle an additional $433^{\circ} \mathrm{C}$. Thus, a completely molten particle has considerably more energy than a particle just below the melting range, despite the temperature difference of the melting range is only $15^{\circ} \mathrm{C}$. This extra energy was also observed to impact the flaming ignition behavior. From Fig. 5 it can be seen that the temperatures required for FI are dif- 
ferent for the aluminum and stainless steel particles, with the aluminum particles requiring lower temperatures, roughly $100^{\circ} \mathrm{C}$ lower, for the flaming ignition of the fuel. Despite the difference in temperature, we can see in Fig. $5 \mathrm{~b}$ that the energy of the particles are fairly similar showing that the particle energy is important for ignition.

\section{Conclusion}

Experiments studying flaming and smoldering ignition of a powdered grass blend by contact with hot aluminum and steel particles have been conducted over a wide range of particle sizes and temperatures. The metals used are representative of those which are known to ignite natural fuels in practical settings. They also have different melting temperatures and physical properties. Both metal particles required similar temperatures to initiate a smolder in the fuel. The smoldering ignition behavior of the large particles is sensitive to to the initial particle temperature. For small particles the smoldering ignition behavior was different - aluminum particles were molten and capable of smoldering ignition at lower temperature than their stainless steel counterparts. The process of melting adds extra energy to the molten particles making ignition at lower temperatures possible. Results from the modeling of the smoldering ignition process support the observed importance of initial particle temperature and energy for large and small particles. However from the results of both the model and experiments, ignition cannot be determined simply by the initial particle temperature and energy.

The timescales for flaming and smoldering ignition after the particle impacts the fuel are also different. Flaming ignition was observed in the gas phase and typically occurred on the order of $10-100 \mathrm{~ms}$. The initiation of a smoldering in- 
dependent of the particle took time on the order of 100-1000s and propagated on the surface and inside of the fuel. The effects of parameters such as those related to the fuel (chemical composition, moisture content, \& morphology), the particle (metal oxidation reactions, \& interactions with other particles/accumulation), ambient conditions (air flow, humidity \& temperatures) all contribute towards determining the conditions required for FI and SI and thus will affect the ignition boundaries reported here. However the problem is complex and must be studied in a parametric fashion. There are still aspects of this ignition process that still need to be studied. Many of the parameters, mentioned above, and processes that where not studied here, such as smoldering to flaming transition, should be investigated. The results presented here provide a basic understanding of spot fire and spot smolder ignition of biomass/natural fuels by hot metal particles and provide data for verification of theoretical models of this relevant ignition process.

\section{Acknowledgments}

The authors would like to thank Kevin Dunnigan, Jimmy Huang, Daniel Weeks and Avyay Panchapakesan for their contributions to this work. We would also like to thank Pedro Rezka who made very useful suggestions for the experimental methods of this study. This research was supported by National Science Foundation Award No. CBET-1066520 and a NDSEG Fellowship.

\section{References}

[1] U. S. F. Administration (accessed December 4, 2014). Http://www.usfa.fema.gov/statistics/estimates/wildfire.shtm. 
[2] California Departent of Forestry \& Fire Protection Investigation Report: Incident number 07-CA-MVU-10432, Technical Report, Ca. Dept. of Forestry \& Fire Protection, 2008.

[3] A. Maranghides, W. Mell, NIST Tech. Note 1635: A Case Study of a Community Affected by the Witch \& Guejito Fires, Technical Report, NIST, 2009.

[4] S. Badger, Large-Loss Fires in the United States - 2011, Technical Report, NFPA, U.S., Quincy, MA 02169, 2012.

[5] Emergency Incident Statistics 2009-2010, New Zealand Fire Service, Wellington, NZ, 2010.

[6] H. Wakelin, Ignition Thresholds for Grassland Fuels and Implications for Activity Controls on Public Conservation Land in Canterbury., Masters, University of Canterbury, 2010.

[7] C. Egan, S. Holland, The AGE National (2009).

[8] G. Ramsey, N. McArthur, Building in the Urban Interface: Lessons from the Jan 1994 Sydney Brushfires, Technical Report, Hobart, Tasmania, 1995.

[9] J. McGuire, M. Law, J. Miller, Domestic Fire Hazard Created by Flying Coals and Sprks (FR Note 252), Technical Report, Borehamwood, UK: Fire Research Station, 1956.

[10] NFPA 51B, Standard for Fire Prevention During Welding, Cutting and Other Hot Work, 2014 ed., App. B, NFPA, U.S., Quincy, MA, 2014. 
[11] Fire Risk Managment Journal (2013).

[12] V. Babrauskas, Ignition Handbook, Fire Science Publishers, Issaquah, Washington 98027, 2003.

[13] M. Ahrens, BRUSH, GRASS, AND FOREST FIRES, Technical Report, National Fire Protection Association, U.S., Quincy, MA, 2013.

[14] M. B. J. C. M. B. K. A. R. S. J.P. Prestemon, T.J. Hawbaker, S. Scranton, Wildfire Ignitions: A Review of the Science \& Recommendations for Empirical Modeling, Technical Report, USDA: Forest Service, Asheville, NC, 2013.

[15] V. Rocha, Firefighters fully contain deadly 70,868- acre Butte fire, 2015.

[16] D. Heryford, Taylor Bridge Fire, Wildland Fire Investigation Report, Technical Report, 2012.

[17] G. Rowntree, A. Stokes, Fire Ignition by Aluminium Particles of Controlled Size, Technical Report, 1994.

[18] T. Tanaka, Reports of the Natl. Res. Inst. of Police Sci. 30 (1977) 151-158.

[19] R. M. Hadden, S. Scott, C. Lautenberger, A. C. Fernandez-Pello, Fire Technology 47 (2010) 341-355.

[20] C. Zak, D. Murphy, A. Fernandez-Pello, WIT Trans. on Built Env. 134 (2013) 607-614.

[21] C. Zak, J. Urban, C. Fernandez-pello, Combustion Science and Technology (2014) 37-41. 
[22] J. L. Urban, C. D. Zak, C. Fernandez-Pello, Proceedings of the Combustion Institute 35 (2014) 2707-2714.

[23] J. L. Urban, C. D. Zak, C. Fernandez-pello, in: Fire and Materials Conference.

[24] M. A. Finney, S. S. McAllister, T. B. Maynard, I. J. Grob, Fire Technology (2015).

[25] a. C. Fernandez-Pello, C. Lautenberger, D. Rich, C. Zak, J. Urban, R. Hadden, S. Scott, S. Fereres, Combustion Science and Technology 187 (2014) 269-295.

[26] U. Gol'dshleger, K. Pribytkova, V. Barzykin, Combustion, Explosion, and ... (1973) 99-102.

[27] J. Jones, Journal of Fire Sciences 13 (1995) 350-356.

[28] C. D. Zak, University Of California Berkeley Phd Thesis (2015).

[29] S. Wang, H. Chen, N. Liu, Journal of Hazardous Materials 283 (2015) 536543.

[30] S. Wang, H. Chen, L. Zhang, Journal of Applied Polymer Science 131 (2014) $\mathrm{n} / \mathrm{a}-\mathrm{n} / \mathrm{a}$.

[31] S. Wang, X. Huang, H. Chen, N. Liu, G. Rein, Combustion and Flame 162 (2015) 4112-4118.

[32] Matweb, Matweb: Material Property Data, 2015. 
[33] C. Y. Ho, R. W. Powell, P. E. Liley, Journal of Physical and Chemical Reference Data 1 (1972) 279.

[34] R. Anthenien, A. Fernandez-Pello, The 27th Symposium (International) on Combustion 27 (1998) 2683-2690.

[35] A. Anca-Couce, N. Zobel, A. Berger, F. Behrendt, Combustion and Flame 159 (2012) 1708-1719.

[36] T. Ohlemiller, Progress in Energy and Combustion Science 11 (1985) $277-$ 310.

[37] J. Yang, S. Wang, H. Chen, International Journal of Heat and Mass Transfer 97 (2016) $146-156$. 